\title{
An observational study of a wireless temporal artery bandage thermometer
}

\author{
Henry Thomas Stelfox, MD, PhD • Sharon E. Straus, MD • \\ Farah Khandwala, MSc $\cdot$ John Conly, MD • \\ Jim Haslett, PhD $\cdot$ Stan Zwierzchowski, M Eng
}

Received: 24 March 2010/ Accepted: 2 June 2010/Published online: 15 June 2010

(C) Canadian Anesthesiologists' Society 2010

\section{To the Editor:}

Accurate and precise temperature measurement, which is an important part of a patient's clinical examination, can be obtained from several locations, including the distal esophagus, rectum, bladder, and pulmonary artery. ${ }^{1,2}$ However, measuring temperature in these locations is invasive and impractical for most patients. ${ }^{1}$ A simple reliable accurate and non-invasive method for measuring temperature is needed in clinical practice. Finvers et al. developed a novel non-invasive continuous temperature assessment method using a wireless temporal artery bandage thermometer (WiTAT). ${ }^{3}$ Given the potential value of WiTAT but the absence of clinical data about its precision and accuracy, we performed a prospective evaluation of the agreement in temperature assessment between WiTAT and an established method of core temperature thermometry (bladder).

After Ethics Committee approval and patients' written informed consent, we recruited five males and nine females based on an estimate that a minimum of 14 patients with 12 temperature measurements would be needed to have $90 \%$ power to detect a $0.25^{\circ} \mathrm{C}$ difference in measured temperatures. The patients, ranging in age from 19 to $74 \mathrm{yr}$ and with a minimum range of $1^{\circ} \mathrm{C}$ in their recorded temperatures in the $72 \mathrm{hr}$ prior to consent, were admitted to a

H. T. Stelfox, MD, PhD (ه) · J. Conly, MD · J. Haslett, PhD .

S. Zwierzchowski, M Eng

University of Calgary, Calgary, AB, Canada

e-mail: tom.stelfox@albertahealthservices.ca

S. E. Straus, MD

University of Toronto, Toronto, ON, Canada

F. Khandwala, MSc

Calgary Health Region Research Portfolio, Calgary, AB, Canada medical-surgical intensive care unit (ICU). Temperature measurements were performed hourly and in a rapid sequential manner from the skin overlying the temporal artery (WiTAT) and from within the bladder (Level $1{ }^{\circledR}$ Foley Catheter temperature Sensor, Smiths Group PLC., Rockland, MA, USA) as part of routine clinical monitoring performed by bedside nurses. Wireless temporal artery bandage thermometer temperatures were recorded at foursecond intervals directly into a closed and locked bedside laptop computer (to blinded clinicians and investigators) whose clock was synchronized with that of the ICU's electronic patient information system. Bladder temperature measurements (manufacturer documented accuracy \pm $0.2^{\circ} \mathrm{C}$ in the range of $5-45^{\circ} \mathrm{C}$ ) were displayed continually on the bedside monitor and were recorded hourly directly into the ICU's electronic patient information system with a time stamp.

Temperature measurement agreement between WiTAT and the bladder thermometer was analyzed using the procedures described by Bland and Altman. ${ }^{4}$ Limits of agreement were clinically $\left( \pm 0.5^{\circ} \mathrm{C}\right)$ defined. Mean differences in measured temperatures were calculated along with the standard deviations of the differences using a one-way repeated measures analysis of variance with patient as the classification variable. Statistical analysis was performed using R, version 2.9 (R Foundation for Statistical Computing, Vienna, Austria).

For analysis, we used 999 WiTAT-bladder temperature observations that were recorded within one minute of each other (Figure). The mean difference between temperatures measured by WiTAT and the bladder thermometer was $0.09^{\circ} \mathrm{C}\left(95 \%\right.$ confidence interval $[\mathrm{CI}], 0.02^{\circ} \mathrm{C}$ to $\left.0.16^{\circ} \mathrm{C}\right)$. Agreement between the two devices was better for normothermia $\left(36.0^{\circ} \mathrm{C}\right.$ to $<38.3^{\circ} \mathrm{C}$ ) (mean $0.28^{\circ} \mathrm{C} ; 95 \% \mathrm{CI}$, $0.21^{\circ} \mathrm{C}$ to $0.35^{\circ} \mathrm{C}$ ) than for hypothermia $\left(<36^{\circ} \mathrm{C}\right.$ ) (mean 


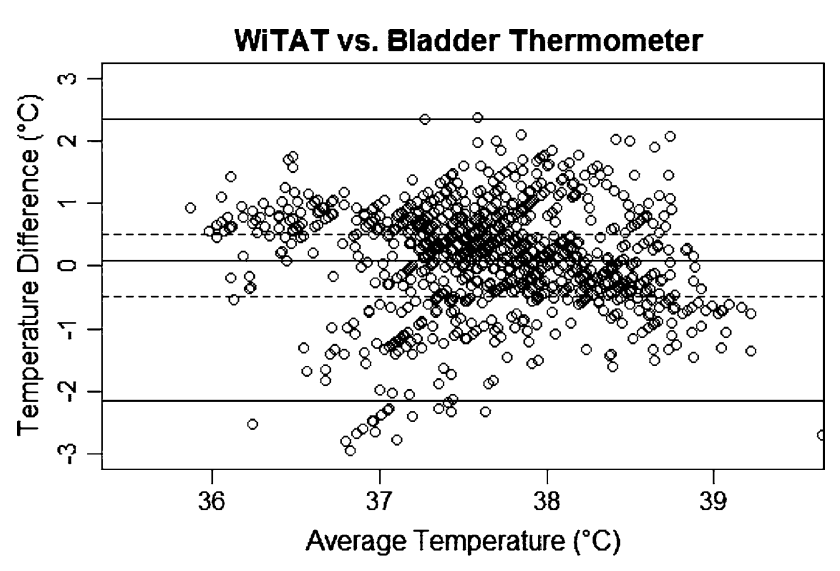

Figure Bland-Altman plot comparing the difference between paired temperature measurements by WiTAT and the bladder thermometer. The middle solid horizontal line represents the mean difference in the two measurements, and the other solid horizontal lines represent $95 \%$ confidence intervals (calculated using one-way repeated measures analysis of variance). The two dashed horizontal lines represent a tolerance of $\pm 0.5^{\circ} \mathrm{C}$

difference $0.88^{\circ} \mathrm{C} ; 95 \% \mathrm{CI}, 0.75^{\circ} \mathrm{C}$ to $\left.1.01^{\circ} \mathrm{C}\right)^{5}$ or for hyperthermia $\left(\geq 38.3^{\circ} \mathrm{C}\right.$ ) (mean difference $-0.71^{\circ} \mathrm{C} ; 95 \%$ $\mathrm{CI},-0.88^{\circ} \mathrm{C}$ to $-0.55^{\circ} \mathrm{C}$ ). ${ }^{1}$ The range of readings was 35.4 to $41.8^{\circ} \mathrm{C}$ for the bladder thermometer and $25.1^{\circ} \mathrm{C}$ to $45.6^{\circ} \mathrm{C}$ for WiTAT. The sensitivity for detecting hyperthermia using WiTAT was 0.49 (95\% CI, 0.42 to 0.56$)$ and the specificity was 0.83 (95\% CI, 0.81 to 0.86 ).

Our data add to a growing body of literature that has noted a lack of agreement between temporal artery and core temperature thermometry. Perhaps these results are not surprising given that skin temperature is affected by factors unrelated to core temperature, including regional perfusion and moisture. ${ }^{1}$ The WiTAT is a novel noninvasive thermometer designed to provide wireless (allowing for remote patient monitoring) and continuous monitoring (eliminating the risk of missing important temperature changes). However, our data suggest that this new technology in its current form does not agree sufficiently with established methods of core temperature measurement to be considered for clinical use.

Acknowledgements We thank Shandra Kimpton for helping to coordinate the study, Linda Knox and Crystal Wilson for assisting with patient recruitment, and Elise Teteris and Alecia Greenough for equipment setup.

Funding sources The project was supported by Medical Ward of the $21^{\text {st }}$ Century.

Competing interests Dr. Haslett is part of a patent application for components of WiTAT, University of Calgary, Calgary, AB, Canada. The project was supported by Medical Ward of the $21^{\text {st }}$ Century. Funding sources had no role in the design, conduct, or reporting of this study.

\section{References}

1. O'Grady NP, Barie PS, Bartlett JG, et al. Guidelines for evaluation of new fever in critically ill adult patients: 2008 update from the American College of Critical Care Medicine and the Infectious Diseases Society of America. Crit Care Med 2008; 36: 1330-49.

2. Laupland KB, Shahpori R, Kirkpatrick AW, Ross T, Gregson DB, Stelfox HT. Occurrence and outcome of fever in critically ill adults. Crit Care Med 2008; 36: 1531-5.

3. Finvers IG, Haslett JW, Jullien G. Wireless temporal artery bandage thermometer. BioCAS 2006: 166-9

4. Bland JM, Altman DG. Statistical methods for assessing agreement between two methods of clinical measurement. Lancet 1986; 1: 307-10.

5. Karalapillai D, Story DA, Calzavacca P, Licari E, Liu YL, Hart $G K$. Inadvertent hypothermia and mortality in postoperative intensive care patients: retrospective audit of 5050 patients. Anaesthesia 2009; 64: 968-72. 